SECCIÓN V * TEMA CENTRAL

Bicentenario 



\title{
El Bicentenario en México: la historia desde la política*
}

Nora Rabotnikof**

\begin{abstract}
Resumen
El artículo analiza la manera en que las conmemoraciones del Bicentenario de la Independencia y el Centenario de la Revolución Mexicana reconstruyen o redefinen significados históricamente sedimentados, en función de la política presente. ¿Qué dimensiones de ese pasado político se revelan como absolutamente "maleables" y cuáles parecen estar relativamente fijadas (por su inserción en mitos políticos pero también en herencias institucionales)?
\end{abstract}

Palabras clave: Conmemoración - Bicentenario - pasado político.

\begin{abstract}
Founding moments of nations seem intrinsically significant. Nevertheless commemorations of the Bicentennial of Mexico Independence and the Centennial of Mexican Revolution will show that the meanings of such events are constructed on the basis of contemporary politics. The article analizes which dimensions of that political past are malleable (and to what extent) and which are relatively fixed (as inserted in myths, but also in institutional legacies).
\end{abstract}

Keywords: Commemoration - Bicentennial - political past.

* Este trabajo se integra en el proyecto de Investigación CONACYT CB2005 Memoria y Política. Las ideas aquí expuestas fueron inicialmente planteadas en el capítulo titulado "De conmemoraciones, memorias e identidades" que aparecerá en el volumen sobre el Bicentenario en México, publicado por la UAM y FCE.

** Doctora en Filosofía. Es investigadora del Instituto de Investigaciones Filosóficas de la UNAM. 


\section{INTRODUCCIÓN}

Este trabajo parte de la hipótesis de que las conmemoraciones de hechos, procesos y personajes a los que se le imputa un aura inaugural de épocas e identidades nacionales sacan a la luz una dimensión no siempre evidente de nuestro acontecer: la relación entre política y tiempo. O una de las maneras en las que puede pensarse esta relación. ¿Qué significa conmemorar un pasado político, aparentemente sancionado por el tiempo (como es el caso de la Independencia y de la Revolución Mexicana), desde un presente políticamente controvertido? ¿Cómo se recupera, se recuerda, se construye o se inventa (y la elección del verbo no es banal) el pasado para celebrar o denostar el presente? ¿Cómo se articula ese pasado con el anuncio, auspiciatorio u ominoso, del futuro? ¿Cómo juega el tiempo en las justificaciones y fundamentaciones de los discursos, debates, proyectos y programas políticos? ¿Qué se conmemora o se recuerda colectivamente? ¿Qué forma de colectividad invoca, instaura o actualiza la conmemoración: la Nación, los ciudadanos, los grupos, las regiones? ¿Y para qué?

México se apresta a conmemorar los doscientos años de la Independencia de España y en la celebración se confluye con otros países de Hispanoamérica. Pero, otra vez aparece la excepcionalidad mexicana: también se cumplen cien años de la Revolución. La imposición calendaria tendrá lugar (y en esto México no es excepción) en un presente de crisis, de transformación e incertidumbre. En términos apocalípticos: en un presente que a veces se muestra "perdido en los tiempos". La continuidad con el pasado ha sido cuestionada, desde la historia y desde la política, y el futuro ya no puede invocarse como fundamento de esperanza ni como garantía de seguridad en el presente. Este "desconcierto" temporal comienza a reflejarse en los modos de invocar al pasado y al futuro a los que se recurre en los discursos políticos y en las intervenciones en los espacios públicos. El recurso a los tiempos, al pasado y al futuro, atraviesa los diferentes escenarios de conflicto, los "sucesivos presentes" por los cuales México se acerca al Bicentenario. Y si bien este "recurso a los tiempos" no zanja las grandes controversias en el espacio público-político (reforma energética, agenda de seguridad, reforma del Estado, cuestión impositiva), da pistas sobre el clima cultural de época. Los aspectos técnicos, financieros, legales y sobre todo políticos de las posturas en pugna en torno a las diferentes cuestiones son complejos, pero una mirada rápida sobre algunos debates pondría en evidencia que el pasado ya no es (como lo fue en el México posrevolucionario) fuente de legitimidad y que el futuro ya no puede fundarse, responsablemente, en el principio de esperanza.

Y esto, más allá de la especificidad mexicana, es un signo de época. El futuro, los presentes futuros, ya no tienen el mismo magnetismo ni ejercen la misma fascinación de antaño. La vocación futurista que animó los grandes proyectos del siglo XX (revoluciones, impulsos reformistas y las distintas oleadas modernizadoras) se ha diluido en el marco de la contingencia y el riesgo.

La cuestión tiene historia y teoría: desde la crítica a la fascinación por lo absolutamente nuevo, hasta el duelo por el fracaso de los proyectos de transformación. Algunos evalúan 
"esta crisis de futuro" como un emergente del fracaso de los mitos apocalípticos de la ruptura radical, o como resultado de la llamada experiencia totalitaria (Hartog, 2001: 16; Huyssen, 2003: 24). Para estas interpretaciones, el atemperamiento del futuro sería así una especie de reacción terapéutica frente a los excesos del futurismo moderno. El saldo de estos fracasos y de estos derroteros críticos fue, entre otros, la destrucción de la idea de Revolución, que, como veremos, no sólo deja de ser una idea guía de futuro sino que también se desmonta como concepto histórico. Para otros, con un tono más melancólico a veces, ello no tiene que ver tanto con las experiencias catastróficas del pasado, sino con un agotamiento de las energías políticas o con un debilitamiento de la creatividad y la imaginación política (Maier, 1993: 150). Lo cierto es que, para regodearse en la pérdida, para celebrar ese eclipse del futurismo como un paso civilizatorio o para exaltar el consumo en el presente "desde la década de 1980, el foco ha pasado de los presentes futuros a los presentes pasados, y este pasaje en la experiencia y la sensibilidad del tiempo debe ser explicado histórica y fenomenológicamente" (Huyssen, 2003: 11).

Si por el lado del futuro la nueva sensibilidad temporal estaría aludiendo a una pérdida de luminosidad (la luz ya no viene de la utopía, de un mañana que justifica los sacrificios en el presente, y ni siquiera de la devaluada idea de "proyecto"), hacia el otro, estaría haciendo referencia a una obsesión con el pasado. Pero a una obsesión de nuevo tipo, que se manifestaría en la pasión archivística (Eiss, 2005: 301), en el boom memorial y, para el tema que nos interesa, en la profusión de conmemoraciones de todo tipo. Se ha mencionado un exceso de memoria (Maier, 1993), un abuso (Todorov, 2001) y con el estilo inaugural de cierta retórica francesa de "la era de las conmemoraciones" (Nora, 1992: 4687). A primera vista, entonces, si el "futuro" de los proyectos políticos se convierte, en el mejor de los casos, en escenarios alternativos y contingentes, y si el clima de época señala una pasión por el pasado de nuevo tipo, ello permitiría diagnosticar una nueva vuelta de tuerca en la relación entre historia y política.

Detengámonos un momento en esta llamada era de las conmemoraciones. Más allá de sus rasgos hiperbólicos, la consigna refiere a tres dimensiones que pueden ser distinguidas. En primer lugar a lo que podríamos Ilamar la confluencia de determinaciones aritméticas: hay una presión del calendario, que parece independiente tanto de la relevancia del acontecimiento como de su significación para el presente: "Aquí no es decisiva la historia sino la aritmética [...] la relación entre la misma conmemoración y el pasado conmemorado no se origina en el carácter histórico de ambos o de cada uno, ni en el tipo de evolución histórica que los conecta (como era el caso del historicismo que lo estudiaba porque creía que el presente es resultado de la evolución de ese pasado), sino en un hecho contingente y puramente aritmético" (Ankersmith, 2001: 165).

En segundo lugar, y de manera más puntual, podemos pensar que 1989, el bicentenario de la Revolución Francesa marcó, en los ámbitos académicos, un punto importante en lo que Ilamaríamos la construcción del objeto de estudio "conmemoración". En algunas posturas teóricas ello llevó a que ésta se constituyera en un objeto de estudio propio: como ritual cívico, como acto de memoria pública o como acto político tout court (Nora, 1992; 
Wolin, 1989: 82). Una consecuencia fue el reconocer que las grandes conmemoraciones cívicas también son una ocasión de invocación de la historia (o de creación) que no pasa directamente por la "historia de los historiadores". Es decir, que las conmemoraciones habilitan con más fuerza a nuevos actores políticos a "decir la historia" (medios, publicistas, políticos, intelectuales en general).

Por ello, en tercer lugar, esto lleva a pensar la conmemoración como forma específica de relación con el pasado. Una forma que se distingue de la historia (como aproximación disciplinariamente pautada), que se distingue de la llamada "memoria viva" (de la cual son portadoras una o más generaciones que fueron actores de los hechos pasados) pero que, se afirma, contribuye a su vez a la formación de la memoria y la identidad colectiva. Esta forma de relación con el pasado será también objeto de diversas interpretaciones (el pasado "renace", se "hace presente", está absolutamente inerme o es objeto de usos políticos en función de la legitimación política o de la construcción de nuevas identidades).

\section{LA FORMA CONMEMORACIÓN: ¿IMPERATIVIDAD O MALEABILIDAD DEL PASADO?}

Tomar a la conmemoración como tema, pone en cuestión, entre otras cosas, el monopolio de la historia en el abordaje y el trazado de nuestra relación con el pasado. Por ello, en la variada literatura sobre memoria colectiva, un lugar especial está reservado a las prácticas sociales de conmemoración, pues se supone que a través de ellas los grupos humanos mantienen o reconstruyen una concepción o una imagen de su pasado. Desde la antropología, la sociología y la psicología social se ha señalado que esas prácticas conmemorativas resultan centrales para mantener la continuidad de la vida social y la identidad de la comunidad (Paddem, 1992: 207; Connerton, 1989: 41; Schwartz, 1992: 97).

Más allá de los aspectos relacionados con "la fiesta pública", de manera convencional pero útil para intentar trazar algunas cuestiones que serán puestas en juego en los bicentenarios, podríamos distinguir dos posturas que hacen a la interpretación del tipo de relación o de uso del pasado que se moviliza en la conmemoración. A la primera la llamaremos la tesis del apremio (constraint) o imperatividad del pasado. A la segunda, la ubicamos del lado de la conmemoración como una forma más de construcción de pasado, un pasado que se revela como absolutamente maleable.

Ambas posturas partirían de la afirmación de que el presente es el tiempo de la memoria y la conmemoración, y ambas reconocerían que son los intereses, las necesidades, los miedos y las ideas del presente los que dirigen la aproximación al pasado. Ambas afirmarían también que la conmemoración, como ejercicio de memoria colectiva, es una operación selectiva, que combina recuerdo y olvido.

Pero la primera postura, la de la imperatividad, enfatizaría la continuidad o, mejor dicho, la necesidad de continuidad, en especial la continuidad identitaria de la comunidad o del grupo a través del tiempo. En esta caracterización, se reconoce el cambio de creencias y las visiones selectivas sobre el pasado. Pero el supuesto implícito es que las creencias sobre 
el pasado deben sobrevivir a los cambios de la sociedad para que la unidad y continuidad de ésta no se vean erosionadas. En el extremo, la función de los ritos conmemorativos no sería tanto transformar el pasado poniéndolo al servicio del presente, sino la de revivirlo, reproducirlo, para reactualizar así el sentido de comunidad. De esta forma, en la conmemoración, la sociedad "renueva el sentido que tiene de sí misma y de su unidad" (Durkheim, 1982). El concepto de tradición de Shils recogería esta idea: la imagen de una época o figura histórica no se concibe y se elabora de nuevo en cada generación, sino que se transmite según un patrón guía, que dota a las diferentes generaciones de una herencia compartida. Aun reconociendo disenso, innovación y apatía en relación a la memoria y la tradición, algunos argumentan que tiene que haber algo más, al menos algún objeto cultural que tenga continuidad y sobre el cual se pueda disentir, innovar o ser apático (Spillman, 2003: 163). En particular, las memorias colectivas compartidas proporcionarían un orden temporal que contribuye al establecimiento de fronteras intergrupales y de redes de solidaridad (en nuestro caso, elementos de una mexicanidad o de herencia compartida en torno al legado del México postrevolucionario).

La segunda postura, por el contrario, pone el énfasis en las condiciones presentes de esa reconstrucción, recuperación o invención del pasado, subrayando a veces el cambio en las formas de construir temporalmente ese pasado (como pasado-pasado, como pasado-presente, como pasado-futuro) en los distintos presentes (Koselleck, 2001, 2003). En nuestro caso, sería el presente mexicano el que coloca de manera temporal a la Revolución, por ejemplo, como un pasado definitivamente "concluido" y lejano, o como un pasado que opera en el presente y que no termina de pasar, o como una promesa de futuro que fue congelada, traicionada, olvidada. Aquí, el foco estaría puesto en la incidencia de las condiciones políticas y culturales de cada uno de esos presentes en los que se realiza la conmemoración. Si en la primera postura se pone énfasis en el carisma originario del acontecimiento o personaje conmemorado y en el requisito de la continuidad identitaria, aquí, en cambio, es el contexto presente de la conmemoración el que orienta, de manera central, el contenido y la forma de lo conmemorado (Schwartz, 1992: 98).

La perspectiva que acentúa la imperatividad del pasado sigue asimilando la ritualidad conmemorativa a la liturgia religiosa. En ese sentido, los rituales conmemorativos (ubicados, para nosotros, en el nivel de la conmemoración de hechos históricos o de significación política) producen una "presentificación" y una reactualización del pasado (Connerton, 1989: 46). Actualizan un nosotros, en este caso político (los hijos de la Revolución, los mexicanos, la Nación). Se subraya entonces la dimensión performativa de la conmemoración: recordar juntos, conmemorar es crear communio.

Esta idea de la conmemoración sometida a "los imperativos del pasado" resulta más provocativa para explicar las continuidades a largo o mediano plazo y, sobre todo, para marcar algunos límites al abanico de reactualizaciones posibles. Parece proporcionar una explicación más fuerte de memorias colectivas persistentes, al ubicar parte del poder y perdurabilidad en el significado mismo del evento pasado. Así, se pone el acento en las imposiciones del pasado y se "sostiene la idea del carisma de narrativas transgeneracionales compartidas, un carisma 
que se basa en el imperativo funcional de un orden temporal compartido. Independientemente de las fuerzas institucionales, algo intrínseco al significado de algunos eventos del pasado genera su recuerdo colectivo sostenido en el tiempo" (Spillman, 2003: 167).

Si interpretamos el significado de los acontecimientos del pasado no como una "propiedad" del pasado, no como carisma en sentido sustantivo (el carisma de gracia o el carisma del líder), sino como la riqueza o "multivalencia semiótica que genera lazos entre símbolo y referente que son menos posibles de ser bloqueados o suspendidos" (Spillman, 2003: 168), la idea resultaría menos fundamentalista de lo que a primera vista podría parecer. En términos más simples, serviría para reconocer que algunos eventos y objetos siguen ofreciendo una base más significativa tanto para la reivindicación como para la contestación. Y que esto les otorga una relevancia que hace difícil que se borren fácilmente de la memoria colectiva. Es decir, una significatividad (construida) que hace que su memoria perdure en el tiempo. Y que, por otra parte, limita el abanico de apropiaciones o interpretaciones posibles. Es decir, nos obliga a reconocer que si bien todo pasado es reinterpretable, no todo pasado es reinterpretable de cualquier manera. Bajo otra descripción, esta idea de la constricción del pasado aparece en las teorizaciones acerca del mito político. Hablar de la Revolución Mexicana como mito no significa (salvo en las visiones más ingenuamente ilustradas) pensarla como invención o como acontecimiento que no tuvo lugar o que no tuvo lugar del modo como lo cuenta la historia. Significa otorgarle una relevancia histórica como organizadora de una identidad (nacional en esos casos), como reservorio de sentido disponible para otros usos, una pluralidad o excedente de sentido que puede ser recompuesto, pero cuyas posibilidades de recomposición no son infinitas.

En cuanto al orden temporal, la tesis de la imperatividad del pasado supone, además del énfasis en acontecimientos a los que se le adjudica un papel fundacional, la continuidad, como imperativo funcional (son los orígenes o el comienzo o el principio) que se ve ratificado en cada conmemoración. Por ende, hay una relación que todavía se vive o se debe vivir como orgánica con ese pasado (de allí venimos, somos los continuadores de la obra, somos los herederos). El problema surge, en esta postura, cuando esa relación de continuidad ya no puede darse por supuesta (porque entre ese pasado y el presente se han interpuesto rupturas políticas significativas o acontecimientos traumáticos o dislocaciones radicales en las formas de organización política). Con ello no nos referimos exclusivamente a grandes acontecimientos "parteaguas", sean estos revoluciones, dictaduras, invasiones, crímenes contra la humanidad o cualquiera de esos grandes mojones que el pensamiento instaura para darle una periodicidad inteligible a la historia. Me refiero también a procesos de lenta recomposición social y política, de cambio institucional e ideológico que, a veces estrepitosamente pero las más de la veces de manera casi molecular, van transformando las formas de vivir y de sentir y también de pensar o recordar el pasado.

Y esto no lleva a la postura constructivista o a la afirmación de la "maleabilidad" radical del pasado. Aquí no comparece un presente metafísico ni un tiempo suspendido sino, casi siempre, la idea de estratos de tiempo. Se abre así la posibilidad de pensar, ya no sólo "la forma" conmemoración sino una aproximación comparativa y crítica de esas conmemoraciones 
(Nora, 1992). No es la continuidad en las formas de conmemoración sino las diferencias: por ejemplo, como se festejó la independencia en el centenario en 1910 y en 1921 (Lempérière, 1995). El énfasis se desplaza aquí a las condiciones de producción político-cultural de cada presente. Directivas oficiales orientadas a la conmemoración, instituciones culturales, objetos conmemorativos, registros, archivos, instauración de feriados, monumentos, actividades que influyen en lo que debe ser recordado y olvidado. Las agregaciones generacionales, los intereses hegemónicos, los intereses turísticos o patrimoniales, el papel de la historia como disciplina, son las figuras que en cada presente son señaladas como causalmente importantes en las agregaciones, omisiones e interpretaciones variables de ese pasado conmemorado. Un punto importante en este tipo de interpretaciones es que si bien la distinción entre historia y memoria se mantiene firme (la memoria no parte de la nítida distinción entre pasado y presente ni apunta a explicar y comprender, y una historia crítica no debe tener talante conmemorativo), tampoco parece muy nítida la distinción entre memoria y mito. Ambos son construcciones, ambos son (o pueden ser) capaces de crear comunidad y el problema con ambas no es la verdad o falsedad sino sus efectos de realidad (Huyssen, 2003: 34). A diferencia de la postura anterior, más orientada a la conformación y ratificación de signos identitarios comunes, esta mirada parece facilitar el acceso a la consideración de memorias plurales, fragmentadas y eventualmente en conflicto. $Y$ en todas ellas estarían en juego usos políticos, identitarios o directamente apolíticos (puramente festivos, o trivializados, del pasado). No hay nada de relevancia en el pasado sino que la construcción de un momento original o fundacional se puede desplazar en el tiempo a diferentes pasados (la conquista, los pueblos originarios, la colonia, la independencia, la reforma, la revolución), a partir de las fuerzas políticas hegemónicas, o de las instituciones de producción cultural (fundaciones, ministerios, archivos, etc.) que arman y desarman, trayéndolas al presente, posibilidades culturales diversas de ese pasado.

Dos conclusiones se imponen a la reflexión. En primer lugar si la postura de la imperatividad del pasado da mejor cuenta de las memorias carismáticas en el sentido de la significación histórica de algunos pasados y, hasta cierto punto, de los límites al revisionismo político posible, no puede interpretar, por sí sola, los cambios en las memorias que fueron carismáticas. Si algunas memorias persisten por algo intrínsecamente interpelante, la posterior amnesia histórica de esos acontecimientos se vuelve inexplicable (Spillman, 2003: 168) sin recurrir a explicaciones que remiten a cada presente político. Y, como dijimos, sin recurrir a explicaciones basadas tanto en las políticas de memoria como en las memorias de la política, o también en las graduales pero a veces irreversibles transformaciones históricas.

Al revés, las posturas que ponen el acento en las condiciones de producción políticocultural del presente, en los "agentes o emprendedores de la memoria" y en la posibilidad de alterar, resignificar, borrar u olvidar el pasado a partir de la situación presente, a menudo no pueden dar cuenta de la persistencia o continuidad de ciertas memorias, de las necesidades puestas en juego, de la pervivencia política de los llamados mitos (que precisamente por ello no pueden ser simplemente exorcizados por la denuncia de su carácter mítico). El supuesto es que, en el corto plazo, "se puede cambiar la historia", si se tiene el poder para hacerlo (cambios en los planes de estudios, en los rituales, las ceremonias). O, al menos, que se puede cambiar todo sin mayores costos políticos. 
En segundo lugar, pareciera que la primera interpretación de la función de la conmemoración (imperatividad) necesariamente presupone un sujeto grupal o comunitario definido (cuya identidad se actualiza y se ratifica) en la conmemoración, y cuyos rasgos o referentes identitarios perduran durante lapsos históricos más o menos largos (la República, la Patria, la Nación, el México posrevolucionario). Y que, por ende, nos sirve para pensar aquellos casos en los que se da una relación más directa entre la conmemoración y la memoria colectiva (por la vigencia de largo o mediano plazo de tradiciones compartidas, historias oficiales plausibles aunque críticamente contestadas, instituciones históricamente legitimadas). En otros términos, situaciones en las que la conmemoración todavía se inscribe en un espacio de experiencias compartido, a lo largo del tiempo. Recordemos que por "espacio de experiencia compartido" no sólo se hace referencia al hecho de que todavía se encuentre viva una generación que fue partícipe de los acontecimientos, sino a las experiencias también trasmitidas y, en cierto sentido, ideológicamente convencionalizadas o institucionalmente encarnadas ${ }^{1}$.

La segunda postura, en cambio, parece partir de la idea de que si bien hubo o hay todavía conmemoraciones que se inscriben en continuidad con la memoria viva, la "era de la conmemoración" introduce la novedad de que la conmemoración se ha transformado en un "lugar de memoria", en una memoria que ya no está viva, sino de la que ya sólo quedan huellas. Y que como tal puede ser objeto de una historia. Para esta lectura, la continuidad con el pasado se ha roto y, por ende, no hay nada de ese pasado que no pueda ser reinterpretado o revisado o, en última instancia, construido de otra manera. En esta lectura, la distinción está puesta en la distancia o diferencia radical entre la conmemoración, como forma, y lo conmemorado (el pasado). Se trata de un cambio de época: si la conmemoración, en su forma clásica, podía apelar a la continuidad con el pasado, al ejercicio de una memoria colectiva (ilustrada y alimentada por la historia), a su distinción nítida con las memorias particulares (de grupos, individuos, de los vencidos, etc.) en una especie de celebración unitaria, el arribo de la era de las conmemoraciones estaría marcando precisamente el fin de este modelo "histórico" de conmemoración (Nora, 1992). La tesis de la imperatividad del pasado correspondería a la conmemoración en su forma clásica, nacional, pero hoy un "modelo memorial" se habría impuesto sobre el modelo histórico. Lo que se ha modificado en el diagnóstico epocal implícito en esta perspectiva es, entre otras cosas, la relación entre historia, memoria y Nación.

1 Refiriéndose no a la Nación ni a la Revolución, sino a un mito cofundador de ambas, el mestizaje, Mauricio Tenorio dice: "Ser mestizo pegó como mito nacional no porque fuera una igualdad verdadera, ni una gran idea, sino porque tenía un contenido real: mestizo era el Seguro Social (IMSS), el Fondo para la vivienda (Infonavit), la Secretaría de Educación Pública (SEP), la Central de Trabajadores (CTM), la UNAM, la posibilidad de sacar del Estado todo tipo de prebendas. No fue un total éxito, no. México no era democrático, pero experimentó el impulso de distribución del ingreso y el poder más impresionante no sólo de su historia sino de la historia de las Américas en el siglo XX" (Tenorio, 2009: 201). El compartir un espacio de experiencias entonces también se relaciona con instituciones, con ejercicio de derechos y, en nuestro caso, con la presencia del Estado. 


\section{MUCHAS HISTORIAS, MUCHAS MEMORIAS: PRESENTISMO, IDENTIDADES Y LA CRISIS DEL ESTADO-NACIÓN}

Las reflexiones contemporáneas sobre la memoria, la historia, el tiempo y la política siguen teniendo una impronta nacional, aunque tengan pretensiones globales. Todas ellas tienen aspiraciones generalizadoras: el abuso de memoria, la crítica a la teleología y al reduccionismo, al modelo clásico de relación entre política y ciencia de la historia, la reivindicación o la denuncia del mito, la denuncia del populismo historiográfico, etc. Pero cada quien reivindica o ridiculiza sus propias memorias acalladas, exalta o denuncia sus mitos, hace explícita o no su historia institucional de la historia y se compadece de o sataniza a sus populismos vernáculos.

En general, esas reflexiones nacionales-globales suelen hacer referencia a la fragmentación de tres figuras que estarían marcando tanto un clima cultural como las coordenadas propiamente políticas de la conmemoración: la ruptura de la continuidad dinámica entre pasado, presente y futuro, la fragmentación del campo historiográfico y la crisis del Estado-Nación.

La primera ruptura es la que introduce la hipótesis del presentismo. Desde el punto de vista político, esta hipótesis sugiere que la caída de los socialismos reales y el fracaso de los proyectos revolucionarios, la globalización (como homogeneización temporal y nuevo cosmopolitismo), el despliegue de los fundamentalismos (como tradiciones inventadas en el presente), el auge del acontecimiento (que es Historia en el momento mismo en que tiene lugar), serían las coordenadas y los signos de un presente que se autootorga inteligibilidad, que corta amarras con el pasado histórico y que anticipa el futuro. El anacronismo presente en muchas interpretaciones de la historia pública en México (se juzga al pasado con categorías que están o estaban fuera de la experiencia de los actores), anacronismo muchas veces asumido como posición política, sería también indicativo de este clima cultural. Pero, sobre todo, los riesgos del futuro (violencia generalizada, narcotráfico, crisis) hacen que incluso el principio de precaución o de responsabilidad asuma tonos más módicos: el futuro se juega y se diluye en lo cotidiano, no se sabe bien dónde vamos, basta con tener la sensación de que hoy, todavía, vamos. La necesidad de ratificar (construir o inventar) identidades del presente (la Nación amenazada, el México pluricultural o multicultural, los ciudadanos y ciudadanas del pasado y del futuro, el México profundo, los hombres anónimos, las élites preclaras, o los individuos racionales) se inscribiría en ese clima presentista.

Pero este privilegio del momento presente, que permea la nueva forma de entender la "conmemoración", también ha sido relacionado con fragmentación de la historia como saber disciplinario, con lo que se hace referencia a varios procesos interconectados. Desde la "democratización" y masificación de los estudios universitarios a la profesionalización de la historia como disciplina universitaria y, como consecuencia, a la ampliación y diversificación de las prácticas de los historiadores. Desde la progresiva ampliación y posterior coexistencia de miradas, métodos y campos de estudio (historia social, historia cultural, historia regional, historia conceptual, nueva historia política, historia oral) (Wallenborg, 2006; Ricoeur, 2000; Burke, 2006) hasta el creciente interés público por temas históricos (con la consiguiente aparición del historiador publicista, opinador o experto). 
Esta irrupción del interés público por la historia, la pluralización de enfoques y metodologías y el acceso a los espacios públicos de grupos antes marginados o excluidos, condujo a advertir sobre las limitaciones de la historia propiamente académica para dar respuesta a las necesidades identitarias de nuevos grupos: "La reivindicación de la sociedad civil o la redefinición a partir de los 70, de grupos minoritarios que se sienten excluidos de la historia general, equivocados o con razón, reivindican un reconocimiento inédito por una reapropiación de un pasado mítico o real que legitima una acción política" (Rousso, 1998: 31).

Independientemente de los rasgos extremos o moderados que el proceso de fragmentación del campo haya tenido en México, algo así como sus efectos son evidentes en relación con la historiografía de los dos grandes momentos que serán conmemorados: la Independencia y la Revolución. Para los historiadores, esta pluralización en general es vista como resultado, casi exclusivo, de los procesos internos a la práctica de la historia o, a lo sumo, como resultado del diálogo con otras disciplinas, como la antropología, pero sólo en pocas ocasiones con el sentido político de esa nueva sensibilidad temporal.

La pluralización o la fragmentación del campo historiográfico tiene, al menos, dos consecuencias para la conmemoración. En primer lugar, y en relación con los grandes acontecimientos históricos, tanto la larga duración como de manera más definitoria la microhistoria y la historia regional terminaron liquidando la idea de la Nación-una, la Patria-una y más claramente la Revolución-una. En términos más generales, el pasado-uno, se vuelve menos unificado como objeto y por ende menos compartido ${ }^{2}$.

Por otra parte, si la historia como disciplina científica, centrada durante mucho tiempo en la historia política, événementielle, tuvo una afinidad selectiva con la historia nacional, y la historia social y económica con una historia colectiva (que es la que durante mucho tiempo culminó en la conmemoración de las fechas patrias), las historias regionales y culturales de las minorías (las mujeres, los indígenas, las regiones olvidadas, etc.) parecen guardar una relación de afinidad con "las memorias", entendidas como lo que ha sido marginalizado en el pasado por esa colectividad. En oposición a las memorias oficiales santificadas por la historiografía moderna, la historiografía posmoderna dibuja nuevas líneas de investigación en la forma de contramemorias (Ankersmith, 2001: 154). Valdría la pena recordar que la reivindicación de estas "contramemorias", ligada a la voz de los que no tienen voz, a la historia "desde abajo" tuvo, en ocasiones, resultados paradójicos: en el bicentenario de 1789 las voces más escuchadas y más reivindicadas fueron, efectivamente, las de las víctimas: la Iglesia, el martirio de la Vendée y la tradición monárquica francesa. Por el lado de la historia entonces (de las muchas historias) y de las minorías, la memoria o las memorias, empiezan a ocupar el lugar de la historia nacional.

2 Para quien llegara a México en algún noviembre de los años setenta, aun si munido de un escueto conocimiento de la historia nacional, la conmemoración del aniversario de la Revolución Mexicana sorprendía por su imagen reconciliada de la historia: en Palacio Nacional podían verse mantas con las figuras de Zapata, Madero, Villa y Carranza; la historia tenía un sentido y una dirección y culminaba en Palacio Nacional. 
Pero una tercera fragmentación postulada como escenario de la nueva forma de conmemoración es la que refiere a la Nación, como referente simbólico unitario o unificador. Y de manera menos presente, la referencia a la crisis del Estado. La historia oficial y el modelo clásico de conmemoración suponían, en efecto, una soberanía impersonal y afirmativa -México, la República, la Nación- verdadera razón de ser de rituales conmemorativos en los cuales el Estado era el oficiante y el gran ordenador. Hoy en México ese Estado ha entrado en crisis, como idea y como práctica. Sus atributos básicos han sido puestos en cuestión, desde el monopolio de la violencia legítima hasta la capacidad de recaudación, desde la vigencia de la legalidad en un determinado territorio hasta su papel como referente en los procesos de socialización y educación. Este proceso, que excede con mucho los temas historiográficos y memoriales, se ha visto, con todo, afectado por los desarrollos ocurridos en estos campos. Como se desprende de la reivindicación de múltiples historias (regionales, locales, de grupos específicos, incluso de la vida cotidiana de ciertos sectores o clases sociales), la tendencia es, antes que dar por sentada la unidad nacional preconizada por las versiones clásicas de la Independencia y la Revolución, a preguntar en cambio hasta qué punto puede afirmarse que ambos procesos (la Independencia y la Revolución) contribuyeron a la formación de una conciencia nacional ${ }^{3}$.

El mito de la Nación, que era también una síntesis temporal, una herencia compartida (mítica pero efectiva) y un proyecto de futuro, parece haber sido arrastrada junto con la caída de la articulación temporal teleológica. Lo local y lo cultural son destructores de lo nacional (Nora, 1992: 4067), allí donde este principio tuvo encarnación.

Hoy, en México, las numerosas convocatorias a la conmemoración de nuestro Bicentenario convocan a una visión plural del pasado, Ilaman a las múltiples historias que deben ser contadas (según las regiones, los grupos sociales, el género, la etnia, etc.) sobre la Independencia pero sobre todo de la Revolución. A veces esta característica es tomada como un dato, y se señala sólo que "ahora las cosas son así" a diferencia del pasado (relativamente reciente) en el que la conmemoración era sólo una festividad oficial y oficializada (la ceremonia del grito, el monumento a la Revolución, los héroes que nos dieron patria, la Revolución que hicieron Madero, Villa, Zapata y Carranza), en las que se ventilaba exclusivamente una versión oficial del pasado, que adquiría difusión y consolidaba su hegemonía a través de los libros escolares, los feriados, los monumentos y las efemérides.

Esta situación, que en otros contextos podría vivirse como parte de la normalidad democrática, contrasta en México con la solemnidad ritual y sobre todo con la monopolización oficial de la conmemoración por parte del orden posrevolucionario. El gobierno a cargo de un partido que no se declara heredero de la Revolución (partido cuyo origen se remonta al rechazo de

3 En relación a la historiografía de la Revolución Mexicana, comenta Friedrich Katz (2004: 11): "La historia regional ha intentado mostrar los profundos cambios sociales, culturales y económicos que impulsaron a algunas regiones a la revolución pero que impidieron la participación de otras -o incluso su rechazo abierto en el proceso [...]. ¿Acaso la revolución fortaleció las conciencias y las identidades regionales o, por el contrario, contribuyó a desarrollar una conciencia nacional en México?". 
lo que otros consideran la etapa de realización de los ideales revolucionarios), que tampoco comparte enteramente las versiones hasta ahora oficiales sobre los rasgos de la guerra de Independencia complica las coordenadas de la celebración. En cualquier caso, resultará difícil conmemorar un México a través de los siglos, una continuidad legendaria. Ni siquiera parece muy nítida la continuidad del México moderno, nacido de la Revolución. La idea de herencia histórica común aparecerá cuestionada, si no en la retórica oficial, al menos en el florecimiento de los particularismos, en las diferentes épocas reconstruidas y reivindicadas, y sobre todo en las diferentes formas de colocar nuestro presente respecto de ese pasado (si como pasado original, como fuente de señas de identidad, como pasado-pasado, como lastre histórico, etc.). Queda por verse si el presentismo como signo del clima político, la pluralización o nueva diversidad del campo historiográfico y la crisis del Estado-Nación, frecuentemente señalados como escenarios de las grandes conmemoraciones contemporáneas darán por resultado, como se presagiaba para la conmemoración de la Revolución Francesa, no una conmemoración nacional sino política, es decir, partisana (Nora, 1992: 4695). Pero, ¿podemos hablar en México de historias partisanas?

\section{LOS POLÍTICOS Y LOS CIENTÍFICOS: ¿DEMOCRATIZACIÓN O PRIVATIZACIÓN DEL PASADO?}

A primera vista, es en la retórica política (oficial y no oficial) donde la conmemoración seguirá siendo ofrecida como ocasión de ratificación de identidad y del sentimiento de continuidad o de herencia del pasado. Pero, cabe preguntarse hasta qué punto las expresiones, ceremonias, proyectos e intervenciones en los espacios públicos serán capaces de actualizar algún "significado originario" de ambos procesos o, por el contrario, lograrán transformar su sentido, hasta el punto de volverlos irreconocibles. La intuición de que hay más "límites de sentido" o más restricciones a la capacidad de apropiación para conmemorar la Revolución que la Independencia, es, a esta altura, algo más que una hipótesis. Y no sólo porque la Revolución sea temporalmente más cercana, o porque la imposición calendaria del Bicentenario se aplique estrictamente a la Independencia. La diferencia entre ambas conmemoraciones refiere más bien a la construcción de la Revolución Mexicana como seña de identidad del México moderno, a su lugar en el código de legitimación del régimen posrevolucionario y al consecuente desprestigio de ese pasado posrevolucionario que trajo consigo la llamada "transición a la democracia"4.

En el caso de la Independencia, las diversas interpretaciones (y propuestas de conmemoración) se presentan a sí mismas como el resultado de un proceso de renovación al interior de la disciplina de la historia (historia global, historia conceptual, nuevas perspectivas, etc.) o en

4 Este déficit de legitimidad histórica, o el peso negativo del pasado más reciente comenzó a estar claro desde la campaña electoral del año 2000. El candidato del partido hasta entonces oficial, el partido con "más pasado", no parecía encontrar huellas de ese pasado para reivindicar frente a la consigna del cambio. El pasado reciente era identificado con la corrupción, la ineficiencia y la ausencia de democracia, y el pasado más lejano, fundador del México moderno, no podía reivindicarse sin correr el riesgo de sonar anacrónico frente al empuje modernizador de la oposición. 
general como intentos de reescribir "la historia de bronce", hacerla "más humana" y adaptarla quizás a las nuevas condiciones del espacio público mediático. Muy pocas interpretaciones hacen explícitas sus "lugares de enunciación" o parecen conscientes de las condiciones de posibilidad de su discurso. A veces, se reivindica explícitamente una postura del historiador arqueólogo, que desempeña su labor en la soledad del cubículo académico, persiguiendo sin tregua la verdad histórica y enfrentándose a los seudohistoriadores que hacen "un uso político" de la historia. Es cierto que la crítica a estas posturas (en general provenientes del espacio público político) parten de un modelo reduccionista del quehacer intelectual ${ }^{5}$ y terminan reivindicando una historia de corte militante, no demasiado preocupada por los anacronismos o por el debate historiográfico.

Sin embargo, el lugar ambiguo y discutible de la Revolución parece relacionarse más con el desconcierto político del presente (aunque también confluyen, en ese resultado polémico, los diferentes "revisionismos" históricos). En la encrucijada formada por la erosión "del legado de la revolución", la ausencia de proyecto de país y el nuevo desencanto democrático, las interpretaciones críticas de larga data, conservadoras o progresistas, parecen obligadas a refuncionalizarse en el discurso político del presente ${ }^{6}$.

Una escena relativamente intrascendente, una postal enviada desde nuestro espacio público político, podría ayudarnos a avanzar en la discusión de las tres fragmentaciones antes mencionadas, incorporando a la reflexión más general, las razones y pasiones de lo nacional.

En el discurso inaugural de la comisión oficial encargada del Bicentenario de la Independencia y el Centenario de la Revolución, Felipe Calderón pronunció un discurso que fue evaluado por los escasos comentaristas como rigurosamente ortodoxo en materia de Independencia y Revolución. Puede ser que el discurso fuera redactado por una pluma prí́sta, o que las inercias mentales en materia de historiografía se conjugaran con el desgano que le debe provocar al presidente tener que lidiar con el pasado desde un presente tan confuso. Al concluir su discurso Felipe Calderón hizo referencia al mural de Diego Rivera en Palacio Nacional y advirtió "nos toca a esta generación decidir qué lugar queremos ocupar en ese mural".

5 Comentando el ataque contra la educación, la identidad, la memoria y la cultura por parte de la Secretaría de Educación Pública (al reducir notablemente los contenidos del texto gratuito de historia), José Steinsleger ubica la medida como una vuelta de tuerca más de la dominación neoliberal: "Telón de fondo: el fuego a discreción de los intelectuales que desmitifican la llamada "historia de bronce": Hidalgo y Morelos cometieron "excesos", los jefes de la independencia fueron "bárbaros"; los liberales de la Reforma, "exaltados"; los líderes agrarios de la revolución, "asesinos"; Cárdenas, "estatista" ... ¿qué ofrecen a cambio de envilecer los contenidos libertarios de nuestra memoria nacional?" (La Jornada, 9 de septiembre de 2009).

6 La revisión de las lecturas marxistas de la Revolución Mexicana (revolución "sólo política", populista, bonapartista, etc.) me parece que está por hacerse. Por lo pronto, no parecen ser demasiado visibles en el contexto de la conmemoración. Suponemos que, al basarse en aproximaciones estructurales y objetivistas, no proporcionarían líneas demasiado claras para la conmemoración. 
El famoso mural se titula "La epopeya del pueblo mexicano" y en él se representa la gran historia, contada o pintada desde el momento más productivo y auspicioso de la Revolución. La sangrienta conquista, las luchas independentistas, la construcción juarista de nación, las masas campesinas oprimidas, la clase obrera moderna, Marx y Lenin, un gran relato de la continuidad identitaria desde el pasado indígena hasta las potencialidades futuras de la era revolucionaria. El esplendor del pasado precolombino y el futuro de la industria, la ciencia y el progreso. El pueblo, esencia que deviene sujeto en y por la Historia, vehiculiza la astucia de la razón; las masas desposeídas, humilladas, explotadas irrumpen y se rebelan frente a los explotadores: Ios españoles, la iglesia, los burgueses, el capitalismo, EE.UU. Historia de masas, con algunos personajes míticos, un origen definido, un presente pleno de posibilidades y un futuro abierto.

Es más que seguro que el presidente no esté al tanto de las disputas historiográficas de los últimos 30 años y que desconozca que justamente esa visión de la historia está hoy puesta en la picota. Desde un punto de vista teórico, porque el teleologismo y el sustancialismo han sido sometidos a crítica. Y políticamente porque, se dice, la visión del mundo expresada en el mural que divide al pasado en amigos y enemigos (los colonizadores y los indígenas, los liberales y la Iglesia, los campesinos y la oligarquía, los obreros y el capitalismo e imperialismo), traída al presente polariza, radicaliza y nos condena a la guerra civil, bloqueando los consensos democráticos (precarios, por cierto). Tal vez alguien podría explicarle que aunque es psicológicamente comprensible que un presidente se preocupe por su puesto de honor en la Historia, es casi imposible pensar que un hombre o un sexenio puedan tener cabida en una representación construida sobre el supuesto de que la historia la hacen las masas, y que pretendió el ser poema pictórico que narra la epopeya de un pueblo. O que el mural también representa la apoteosis de los sueños futuristas y que, por ende, la nueva tonalidad temporal presentista no podría tener cabida en él.

Al comentar la infeliz pretensión del presidente, uno de los pocos analistas políticos que repararon dicha expresión recordó, a su vez, otra anécdota. Alguna vez, al contemplar el mismo fresco de la escalera de Palacio Nacional, un connotado intelectual del Partido Acción Nacional (mentor ideológico del actual presidente) habría expresado, no sin cierta angustia, que "un problema en México es que existen dos historias y la nuestra aquí no aparece". El recuerdo de Castillo Peraza Ilevaba a nuestro analista a poner la preocupación de Calderón bajo una luz política distinta: "Una élite formada en una historia patria conservadora dirige a un país formado en una Historia patria liberal y revolucionaria ¿no estará aquí el origen de muchos de los desencuentros que nos agobian?" (Medina Peña, 2009).

Para este analista, como para el angustiado maestro de Calderón, no se podría hablar de una única historia patria ni de una única historiografía liberal. Aunque la historia patria liberal fuera la hegemónica, consolidada a través de la educación pública, los rituales cívicos, los calendarios y las conmemoraciones (y los murales), otra historia patria habría ido contándose y renovándose en el seno de las escuelas católicas, las asociaciones confesionales y también los recuerdos de familias. Esas dos historias patrias, una oficializada y otra más o menos subterránea, habrían tenido sus antecedentes en el siglo XIX, en las visiones "liberal" y en la 
"conservadora". La versión liberal se articularía en una narrativa épica nacional: exaltación del mundo prehispánico, desprecio por la colonia, épica popular de la libertad desplegada en los tres momentos: Independencia, Reforma y Revolución. Los héroes incuestionados que nos dieron patria: Hidalgo y Morelos, la figura colosal de Juárez. Y su nuevo momento fundacional con las utopías y debilidades de Madero, el heroísmo de Zapata y la visión constitucionalista de Carranza y, posteriormente, la plena realización de la Revolución con el Cardenismo.

La versión conservadora, hasta hace poco mantenida como memoria soterrada en el circuito de la educación privada confesional, las familias, las provincias y las asociaciones católicas, reivindicaría, en cambio, a la dos patrias: la novohispana y la mexicana, conformadas a partir de dos momentos fundacionales, la Conquista y la Independencia. La Nueva España aparecería aquí como multicultural (ahora) y como modelo institucional. Esta versión subraya la continuidad postindependentista, con la salvedad que los liberales exaltados no habrían hecho demasiado por la creación de orden. Para esta versión, reforzada después de la alternancia de 2000, los gobiernos posteriores a la caída del segundo imperio fueron dictatoriales porque no respetaron la Constitución, la Pax porfiriana no habría estado tan mal, Madero habría intentado la transición democrática pero la cuestión se le fue de las manos. La Revolución fue el producto de la modernización que generó nuevos grupos y nuevas aspiraciones, que arrasó con el orden y las comunidades preexistentes ${ }^{7}$. Los gobiernos posrevolucionarios también se caracterizaron por la falta de respeto a la libertad, la democracia y la Constitución.

La hipótesis de las dos historias patrias es discutible y requeriría abundar o ir más allá de las historias regionales y locales y de la memorias privadas para arriesgarse a armar, a partir de ellas, una narrativa que fuera algo así como "otra" historia patria. Un paso ulterior sería mostrar cómo esa multiplicidad de memorias sedimentadas y transmitidas por las familias, la Iglesia, las asociaciones, llegó alguna vez a constituirse en una síntesis "partisana". Por lo pronto, la distancia entre la élite formada en una historia patria conservadora y la población formada en la historia liberal y revolucionaria resulta insuficiente para explicar la coyuntura política general y la distancia actual entre gobernantes y gobernados o sus desencuentros.

Pero sí podría ser útil para entender los desencuentros o encuentros que signan la conmemoración. No podemos entrar aquí en la discusión acerca de si se puede o no hablar de revisionismo histórico mexicano ${ }^{8}$ y en qué sentido. Lo más interesante de la aspiración

7 La esquematización de las dos historia patrias, por mor de coherencia con los sentimientos de Castillo Peraza, la tomo del artículo de Medina Peña. Pero se podrían armar otras, como la de Alan Knight para la Revolución, más basadas en las tendencias y generaciones de la historiografía (1989). En cualquier caso, es interesante ver cómo el Bicentenario será ocasión de que estas narrativas accedan a un espacio público más amplio. para referir a las nuevas, o a veces no tan nuevas corrientes de interpretación histórica que discuten con la vieja ortodoxia historiográfica. En la tradición marxista tiene un significado más directamente político doctrinario. También esto ocurre en el caso argentino. Para México, escribe Elías Palti, "el término se ha visto degradado a una suerte de contraseña por la cual se constataría simplemente la supuesta actualidad y validez académica 
presidencial y del comentario no es el desconocimiento de los debates historiográficos ni las inercias conceptuales evidenciadas: la anécdota toca, me parece, algunos tópicos importantes de la conmemoración, el tiempo, la historia y la política en México. Tomemos, para concluir, cuatro lecturas posibles de esta hipótesis de esas dos historias patrias y veamos cómo ello incide para pensar hoy la relación entre historia y política.

Primera lectura: las historias partisanas son un fastidio para la conmemoración pero no inciden necesariamente en la política presente. Esta primera lectura se hace cargo de las dificultades que supondrá celebrar el Bicentenario y, más aún, de lo incómodo que supone "gobernar una nación con cuya inmensa mayoría se encuentran en constante estado de disonancia cognitiva, y tener que respetar los ritos y símbolos heredados". Pero poco se puede hacer, "si la nación se educó en el paradigma de los vencedores" (y la élite gobernante, en el de los vencidos). Finalmente, si el Bicentenario resulta tan engorroso para el Ejecutivo, aquí como en otros rubros, la abdicación del lugar del Estado Nacional tiene sus consecuencias pluralistas: muchas comisiones, muchas asociaciones y personas con conciencia patriótica toman su lugar. Si no hay Estado Nacional que pueda ser el gran oficiante, una sociedad civil inquieta y plural, toma, también en este caso, su lugar (Medina Peña, 2009).

Los dos relatos patrios no inciden en la política del día a día, ni hace falta que lo hagan. En cuanto a las grandes decisiones que afectan el rumbo del país, basta con que las ofertas gubernamentales se fundan en las urgencias del presente (la guerra actual contra el narcotráfico, el deterioro incontrovertible de la industria energética, la necesidad inminente de reformas, la crisis financiera). Para ello, es suficiente invocar el pasado inmediato (el de la corrupción y la ineficiencia de régimen priísta). El ayer más lejano es más flexible (la independencia, el laicismo, la nacionalización petrolera, la afirmación de la soberanía, la rectoría estatal, el Ilamado legado de la Revolución). En todo caso, no es necesario cuestionarlo siempre como pasado sino, precisamente, ubicarlo en ese lugar de lo ya pasado, diferenciado de un presente que requiere transformación. El pasado está pasado, no es necesario revisarlo siempre pero, sobre todo, no hay continuidad con él que pueda reivindicarse productivamente en el presente. El futuro es un mañana ominoso que ya está presente (agotamiento de las reservas, aumento de la dependencia, imposibilidad de competir, violencia generalizada, crisis global). Si hay dos historias patrias, ellas pueden pesar en las políticas de la conmemoración, pero la historia no importa demasiado para las urgencias del presente, ni siquiera como mecanismo de legitimación (sobre todo cuando de lo que se trata es de transformar esos legados) ${ }^{9}$. No se ve claro cuál es el lugar que la alternancia podría tener en el mural de Rivera, pero, finalmente, tampoco se ven muy claras cuestiones más importantes.

del texto, libre ya del tipo de teleologismo y nacionalismo que impregnó la antigua historiografía liberal" (Palti, 2007: 19). Para Alan Knight (1989), en la historiografía de la Revolución Mexicana, el término corresponde a tres de las grandes síntesis históricas de la Revolución, y se caracteriza sobre todo por la progresiva negación del carácter popular y agrario de la Revolución.

$9 \quad$ Este parece ser, en general, el marco temporal de las ofertas gubernamentales, desde la reforma energética hasta la reorganización de las políticas sociales. 
Segunda lectura: la historia importa porque ella legitima nuestra política y, sobre todo, ratifica nuestra autoridad moral. La izquierda suele recuperar el pasado más distante $^{10}$, legitimatorio de identidad (los usos y costumbres, el México profundo y la herencia republicana, la nacionalización petrolera, la afirmación de la soberanía, la Revolución Mexicana), plasmado, en ocasiones, en el texto constitucional (la Constitución como pacto de identidad). No se niega el pasado inmediato o reciente (la corrupción, el surgimiento de la violencia, la explotación, la ineficiencia) pero se lo inscribe en un pasado más largo, de manera alternativa como resultado de las falencias de la Revolución, o de la traición a sus principios, o también enmarcándolas en un ciclo concluido por la transición.

La historia patria del nacionalismo revolucionario acentúa aquí sus ejes antiimperialistas y anticapitalistas, zaga de los pobres contra los ricos, de los pueblos contra la dominación extranjera. No es una historia de las instituciones y su estabilidad, ni tampoco una historia de las ideas o los lenguajes, sino de esas alternativas que, en cada momento histórico, tuvieron la voluntad política y la ética necesaria para cuestionar el diseño institucional y las relaciones de poder que éste ocultaba ${ }^{11}$.

Pero el futuro tampoco es aquí plenitud de promesas. No es la alternativa auspiciosa que surgiría de otra política, sino que es el eventual resultado de la resistencia del presente a una catástrofe cuyo advenimiento parece acelerarse. En ese escenario, el pasado fundacional brinda señas de identidad a las que es necesario aferrarse y es la piedra de toque de las fidelidades y traiciones del presente. Una historia que tiene sus héroes que en cada etapa defendieron consecuentemente la igualdad y la justicia, pero cuyo protagonista fue el pueblo mexicano (indígenas, campesinos, trabajadores y pobres). Con ello se exacerba la mitología de la prolepsis y se hace caso omiso del debate historiográfico, pero se amplían las posibilidades de inscripción en el mural.

Tercera lectura: podemos vivir sin historias patrias (y sin murales). En el otro extremo del espectro, se cuestiona la historia patria oficial en nombre de la gente anónima, no el pueblo mexicano ni los explotados, sino "la multitud de mexicanos valiosos que han ido construyendo el país en la vida cotidiana, laboriosa, constructiva y llena de pequeños triunfos creadores" (Zaid, 2009). Desde esta perspectiva, lo que hoy se festeja como

10 Este pasado va más allá de la Revolución Mexicana. En el caso de Andrés Manuel López Obrador, se acerca bastante a la narración épica de Rivera: "Los padres de la patria lucharon contra el colonialismo español, pero también, de manera contundente, a favor de la igualdad y contra el racismo y la opresión... por eso, en la víspera del Bicentenario más que el festejo frívolo al estilo porfirista, debemos refrendar el compromiso de seguir luchando para hacer realidad los anhelos que dieron origen a esa gran gesta histórica del pueblo y de sus dirigentes" (Discurso pronunciado durante la ceremonia conmemorativa por el aniversario del inicio de la Independencia Nacional, 16 de septiembre de 2009).

11 "No olvidemos que Hidalgo, Morelos Juárez, Madero, Villa, Zapata y los hermanos Flores Magón, lo dieron todo por sus convicciones, por sus ideales y por su profundo amor al pueblo. Les hablo así porque, como lo han demostrado, al igual que muchos otros mexicanos, no se dejan engañar ni están dispuestos a claudicar o a rendirse" (López Obrador, Ibíd). 
Independencia o como Revolución no fueron fechas fundacionales sino irrupciones devastadoras, condensaciones de violencia que interrumpieron la marcha acompasada de la civilización y la construcción del país ("Destruyeron muchas cosas valiosas. Causaron muertes injustificables. Lo que los indios, mestizos y criollos habían venido construyendo después del desastre de la Conquista alcanzó un nivel sorprendente en el siglo XVIII, que se perdió con los desastres de la Independencia y la Revolución"). No hay héroes que merezcan reconocimiento, ni los necesitamos. Hidalgo fue un irresponsable que usó a la Virgen de Guadalupe para legitimar un movimiento que degollaba civiles, Madero otro irresponsable que abandonó la lucha ciudadana para dejarse arrastrar por un movimiento de asesinos, Pancho Villa, sin más, un bandolero. No fueron revoluciones, ni una grande ni muchas, fueron guerras civiles. No fueron héroes que nos dieron patria sino asesinos.

Desde la vida cotidiana, la microhistoria no complementa críticamente a la historia política nacional, sino que la desplaza. No conmemoremos dos fechas, que deberían llenarnos de vergüenza, sino dos largos siglos de construcción de país. Si hay alguna continuidad con el pasado es con esa gente laboriosa e industriosa, tal vez antecedente de la contemporánea sociedad civil. Pocas referencias hay a la existencia de historias partisanas, como si el unanimismo político prí́sta, sólo pudiera ser contestado desde la diversidad múltiple y anónima de la sociedad civil. O como si los muy precarios consensos del presente pudieran proyectarse, sin heridas hacia el pasado. Aquí no hay mural, ni hace falta.

Última lectura: desencantar la historia patria, la historia para los historiadores. En general, la academia ha adoptado una actitud crítica ante las conmemoraciones que vienen, y las preocupaciones han girado centralmente en torno al papel de la historia como disciplina, al compromiso cívico del historiador, a la distancia que impone la mirada histórica, y a los usos políticos del pasado. Aunque el Bicentenario ha sido ocasión de gran cantidad de seminarios, proyectos y eventos político-académicos. También ocasión para disparar las participaciones de los historiadores en el espacio público y debatir acerca de la relación entre difusión de la historia y memoria pública. En general, la referencia crítica es a una única historia patria, sin menciones a historias partisanas o a revisionismos anteriores (al menos más allá del siglo XIX). Es como si la historia nacional hubiera sido exclusivamente la historia oficial, liberal y después priísta, y ésta recién se pusiera en cuestión a partir de las novedades producidas por la historia como disciplina (historia regional, de la vida cotidiana, de las minorías, individualismo metodológico, etc.) o de los llamados revisionismos (históricos).

Pero cuando se trata intervenir en el espacio público político, esos procesos internos a la disciplina parecen menos internos y más políticos. Historiadores más ligados a la "historia nacional" y al nacionalismo revolucionario, arrecian con las denuncias a la historia "subjetiva" que presume que el valor de la historia no está anclado en los hechos sino en la visión de quien los narra, y que con ello "desmitifican a nuestros próceres y pretenden reescribir la historia oficial para que se escriba otra al servicio de poderes más sutiles pero 
más perniciosos"12. O cuando se señala que está de moda pegarle duro a los liberales. O más seriamente, cuando se pone en juego el tema de la enseñanza de la historia en la escuela y se señalan los peligros que entraña el recorte a los programas de la materia.

Cuando se mencionan, las dos historias patrias son puestas en cuestión desde una mirada que quiere ponerse más allá de las intenciones partisanas. A veces, porque se piensa que cualquiera de las dos no hace otra cosa que fomentar la guerra civil y porque la historia debe estar al servicio de lo bueno y lo justo, de la libertad y la fraternidad. Otras veces porque la criticada historia nacional puede ser reemplazada por una memoria nacional, de una nación que no se funde en triunfos y derrotas compartidos sino "sobre los vínculos que logre materializar como comunidad de derecho y de derechos" (Pani, 2009). En general se reivindica una historia crítica, que acepte la complejidad histórica y que se resista a su posible simplificación en aras de la divulgación.

Pero cuando, con mayores o menores reticencias, la historia académica intenta "salir a la calle" y llegar a un público más amplio, tiene que competir con la ficción (las novelas históricas, las biografía noveladas, las obras de teatro) que parecen más efectivas en el cumplimiento de "bajar a los héroes de su pedestal" o cuestionar la historia de bronce. Frente a este tipo de escritura, pareciera que la disciplina tampoco encuentra demasiados recursos en las disputas de los últimos años y no queda más que volver a la objetividad científica, al recuento de los hechos, a la rigurosidad del tratamiento de las fuentes, al tiempo corto, con el agregado, en el mejor de los casos, de un toque de contexto cotidiano. Si a veces se intenta mostrar a individuos que, con mayor o menor tino, enfrentaron situaciones inéditas y altamente complejas, la sombra del "proyecto nacional", aunque sea como introducción, sigue siendo el marco que permite insertar hechos y personajes en un continuo histórico de larga duración. En todo caso, la pretensión es a una historia matizada y ponderada, que se resiste a ser trama del mural de la epopeya del pueblo, pero que tal vez busca, sin reconocerlo, armar otra trama (la de la comunidad de derecho, la de las víctimas olvidadas o la de la historia objetiva $)^{13}$.

Más allá del dispendio o la hipocresía, las conmemoraciones pueden ser ocasiones privilegiadas para observar, desde otra perspectiva, el tiempo y la política, las formas en

12 Como lo expresara el nuevo presidente de la Academia Nacional de Historia y Geografía, el senador y presidente del Partido Convergencia, Luis Maldonado Vega, cuando instó a recordar el período inicial posrevolucionario en el que "México erigía las bases de un nuevo proyecto nacional, que aspiraba a armonizar en su justo equilibrio los anhelos de reivindicación social con la paz orgánica de la República. ... momento de la ponderación más honda y cabal de lo nuestro, de lo medular, de lo propio, el proemio de un nacionalismo cultural que aspiraba legítimamente a elevar a un primer plano los valores de nuestra identidad, rechazando la reproducción de modelos ajenos que ahogaran su significado propio" (La Jornada, 11 de septiembre de 2009).

13 Nexos, una revista dirigida a la esfera de la opinión pública convoca a un foro de historiadores con el título Delirios de la Independencia. En la editorial se denuncian las deformaciones de la verdad histórica y, al mismo tiempo, "se apela a un pasado abierto que pide a gritos su independencia de la fábula, el patrioterismo, la retórica y la mentira". Se trata de establecer hechos incontrovertibles que hacen a la verdad histórica (que Hidalgo fue un cura incendiario arrepentido, Iturbide un estadista imposible, la independencia una epopeya discutible y un desastre real, la rebelión un asunto de curas) (Nexos, septiembre 2009). 
las que los grupos sociales viven o sobreviven a su pasado y anticipan o no su futuro. Y para pensar también cómo la historiografía en los distintos momentos, asume su propia historia y reconoce, cuestiona o ignora su dimensión política. Estado, Nación, México, clase, entendidos como conceptos históricos ponían el pasado a distancia del presente pero también proporcionaban un puente para llegar a él. Las múltiples entradas, los distintos hilos genealógicos, los diversas necesidades identitarias nos brindan un mapa demasiado abigarrado como para llegar a un territorio común. Queda también por verse si esta proliferación de historias y memorias es signo de una democratización, que ahora ha alcanzado al pasado. O, por el contrario, si la crisis de la idea de Nación y sobre todo el debilitamiento de los proyectos colectivos (hacia el futuro) han convertido al pasado, también para nosotros, en un país extranjero.

\section{BIBLIOGRAFÍA}

Ankersmit, F. R. (2001): Historical Representation, Standford University Press, California.

Barrón, Luis (2004): Historias de la Revolución mexicana, FCE-CIDE, México.

Blouin, Frances X. y William G. Rosemberg (2005): Archives, Documentation and Institutions of Social Memory, University of Michigan Press, Michigan.

Burke, Peter (2006): La revolución historiográfica francesa, Gedisa, Barcelona.

Connerton, Paul (1989): How Societies Remember, Cambridge University Press, Cambridge.

Durkheim, Émile (1982): Las formas elementales de la vida religiosa, Akal, Madrid.

Eiss, Paul (2005): "Redemption Archives. Remembering the Future in a Revolutionary Past", en Frances X. Blouin y William G. Rosemberg: Archives, Documentation and Institutions of Social Memory, University of Michigan Press, Michigan, pp. 301-317.

Florescano, Enrique (coord.) (2009): Arma la Historia, Grijalbo, México.

Furet, François (1979): Penser la Révolution Française, Gallimard, Paris.

Gillis, J.R (ed.) (1994): Conmemorations: The Politics of National Identity, Princeton University Press, New Jersey.

Halbwachs, Maurice (1997): La mémoire collective, Albin Michel, Paris.

Hartog, François (2003): Régimes d'historicité. Présentisme et experiences du temps, Seuil, Paris.

Hartog, François y Jacques Revel (2001): Les usages politiques du passé, Éditions de L'École des Hautes Études en Sciences Sociales, Paris.

Huyssen, Andreas (2003): Presents Pasts. Urban Palimpsests and The Politics of Memory, Standford University Press, California.

Knight, Alan (1989): "Interpretaciones recientes de la Revolución Mexicana", Secuencia, № 13, Instituto de Investigaciones Doctor José María Mora, México, enero-abril.

Koselleck, Reinhart (1992): Futuro Pasado, Paidós, Barcelona.

(2001): Los estratos del tiempo: estudios sobre la historia, Paidós-ICE de la Universidad Autónoma de Barcelona, Barcelona.

(2002): The Practice of Conceptual History, Standford University Press, California. 
(2003): Aceleración, prognosis y secularización, Pre-Textos, Valencia.

LaCapra, Dominick (2004): History in Transit: Experience, Identity, Cornell University Press, Ithaca.

Lempérière, Annick (1995): "Los dos centenarios de la Independencia mexicana (1910-1921)", en Historia Mexicana, Vol. XLV, № 2, El Colegio de México, México, pp. 317-352.

Lechner, Norbert (2006): "Construcción social de las memorias en la transición chilena", en Elizabeth Jelin y Susana Kaufman (comps.): Subjetividad y figuras de la memoria, Siglo XXI, España.

Le Goff, Jacques (1998): Histoire et mémoire, Gallimard, Paris.

Lowenthal, David (1985): The Past is a Foreign Country, Cambridge University Press, Cambridge.

Maier, C. S. (1993): "A Surfeit of Memory", en History and Memory: Studies in the Representation of the Past, № 2.

Middleton, David y Dereck Edwards (1992): Memoria compartida: la naturaleza social del recuerdo y el olvido, Paidós, Barcelona.

Morales Moreno, Luis Gerardo (comp.) (2005): Historia de la historiografía contemporánea, Instituto Mora, México.

Nora, Pierre (ed.) (1992): "L’ère de la conmémoration", en Les lieux de mémoire, Vol. 3, Gallimard, Paris.

Olick, Jeffrey (2003): States of Memory: Continuities, Conflicts and Transformations in National Retrospection, Duke University Press.

Palti, Elías (2002): La Nación como problema, FCE, Argentina.

(2007): El tiempo de la política, Siglo XXI, Argentina.

Pennbaker, James et al. (1997): Collective Memory of Political Events, Lawrence Erlabaum, New Jersey.

Robin, Regine (2003): La mémoire saturée, Stock, Paris.

Rousso, H. (1998): La hantise du passé, Textuel, Paris.

Shils, Edward (1981): Tradition, University of Chicago Press, Chicago.

Spillman, Lyn (2003): "When Do Collective Memories Last? Founding Moments in the United States and Australia", en Jeffrey Olick: States of Memory, Duke University Press, pp. 161-193.

Schwartz, Barry (1992): "La reconstrucción de Abraham Lincoln", en D. Middleton y D. Edwards (comps.): Memoria compartida, Paidós, Barcelona.

Tenorio Trillo, Mauricio (2009): Historia y celebración, Tusquets, México.

Tilly, Charles (2003): "Afterword Borges and Brass", en Jeffrey Olick: States of Memory, Duke University Press.

Todorov, Tzvetan (1994): Une trágedie Française, Éditions du Seuil, Paris. (2000): Los abusos de la memoria, Paidós, Madrid.

Tully, James (1998): "The pen is a mighty sword", Introducción a Meaning and Context, Polity Press, Londres.

Wallenborg, Hélène (2006): L'historien, la parole des gens et l'écriture de l'histoire, Editions Labor, Belgium. 
Wolin, Sheldon (1989): The Presence of the Past. Essays on the State and the Constitution, The John Hopkins University Press.

\section{Artículos de opinión:}

Steinsleger, José: "Gloria a los héroes que nos dieron patria", La Jornada, 9 de septiembre de 2009.

Zaid, Gabriel: "Los asesinos que nos dieron patria", Reforma, 28 de junio de 2009.

\section{En Nexos, 22 de septiembre de 2009:}

Breña, Roberto: "Historia compleja, festejo simple".

González de Alba, Luis: "Mentiras de la independencia".

Medina Peña, Luis: "Las dos historias patrias".

Meyer, Jean: "Qué hacer con el pasado".

Pani, Erika: "Las naciones no cumplen años". 


\section{Normas editoriales}

Para enviar artículos a la Revista de Sociología, los interesados deben cautelar los siguientes procedimientos y normas editoriales.

1. Enviar tres copias impresas, una de las cuales debe contener la identificación del autor con la indicación de un breve currículum: grado académico y ocupación. Además de las copias impresas, se debe incluir un respaldo electrónico del artículo en un CD.

2. En la primera hoja cada artículo debe contener: título, un resumen escrito en inglés y otro en español, que no supere las ciento veinte (120) palabras cada uno, e indicación de tres palabras clave.

3. La extensión de cada artículo no debe superar las diez mil (10.000) palabras. Estos deben ser presentados en formato Word, interlineado doble y letra Times New Roman tamaño 12.

4. Los cuadros y gráficos deben ser presentados en un anexo o apartado final, indicando al interior del texto el lugar de su inserción.

5. Las citas deben ser presentadas entre paréntesis, indicando el apellido del autor y el año de edición del libro o artículo (Offe, 1990; Habermas, 1997). Se debe indicar la página en el caso de referencias y citas textuales (Rosanvallon, 2007: 45).

6. Especificar y numerar los títulos principales al interior del texto, estableciendo un sistema de distinción respecto de los subtítulos y otros apartados.

7. Al final del texto se debe incorporar el listado de la bibliografía citada, indicando el apellido y el nombre del autor, el título del libro o artículo (en cursivas para el caso de libros y entre comillas para el caso de artículos y capítulos), editorial, lugar y año de edición.

Los artículos deben ser enviados a nombre de Comité Editorial de la Revista de Sociología. Departamento de Sociología, Facultad de Ciencias Sociales, Universidad de Chile. Ignacio Carrera Pinto 1045. Tercer Piso. Nuñoa, Santiago de Chile. Fono: (0056 2) 9787781 - 978 7782. Fax: (0056 2) 9787777.

Contacto: revsoc@uchile.cl.

Departamento de Sociología, Facultad de Ciencias Sociales, Universidad de Chile. Ignacio Carrera Pinto 1045. Tercer Piso. Ñuñoa, Santiago de Chile. Fono: (0056 2) 9787781 - 978 7782. Fax: (0056 2) 9787777. 
ANDROS IMPRESORES

www.androsimpresores.cl 